\title{
Risk factors associated with abdominal obesity in suburban adolescents from a Malaysian district
}

\author{
Wai Fong Chew $^{1}$, MMedSc, BSc(Hons), Pooi Pooi Leong ${ }^{1}$, PhD, MSc, Sook Fan Yap ${ }^{1}$, FRCPA, MRCP, \\ A Malik $\underline{\text { Yasmin }}^{1}$, MBBS, FRCPath, Kong Bung $\underline{\text { h hoo }}^{1}$, PhD, BSc(Hons), Gary Kim Kuan Low ${ }^{2}$, MBBS, MPH, Nem Yun Boo ${ }^{2}$, FRCPCH
}

INTRODUCTION We aimed to determine the risk factors associated with abdominal obesity (AO) in suburban adolescents. METHODS This cross-sectional study included adolescents aged 15-17 years from five randomly selected secondary schools in the Hulu Langat district of Selangor state, Malaysia. Waist circumference (WC) was measured at the midpoint between the lower margin of the last palpable rib and the top of the iliac crest. Information on sociodemographic data, dietary habits, physical activity levels and duration of sleep was obtained via interviewer-administered questionnaires. Participants' habitual food intake was determined using a 73-item Food Frequency Questionnaire.

RESULTS Among 832 participants, $56.0 \%$ were girls; $48.4 \%$ were Malay, $40.5 \%$ Chinese, $10.2 \%$ Indian and $0.8 \%$ of other ethnic groups. Median age and WC were 16 (interquartile range [IQR] 15-16) years and 67.9 (IQR 63.0-74.6) cm, respectively. Overall prevalence of $A O$ (> 90th percentile on the WC chart) was $11.3 \%$. A higher proportion (22.4\%) of Indian adolescents were found to have AO compared with Malay and Chinese adolescents. Logistic regression analysis showed that female gender (adjusted odds ratio [OR] 7.064, 95\% confidence interval [Cl] 2.087-23.913; $\mathrm{p}=0.002$ ), Indian ethnicity (adjusted OR 10.164, 95\% Cl 2.182-47.346; $\mathrm{p}=0.003$ ), irregular meals (adjusted OR 3.193, 95\% Cl 1.043-9.774; $p=0.042$ ) and increasing body mass index (BMI) (adjusted OR 2.867, 95\% Cl 2.216-3.710; $p<0.001$ ) were significantly associated with $\mathrm{AO}$.

CONCLUSION AO was common among Malaysian adolescents. Female gender, Indian ethnicity, irregular meals and increasing BMI were significant risk factors.

Keywords: abdominal obesity, adolescents, dietary habits, waist circumference

\section{INTRODUCTION}

Obesity based on body mass index (BMI) has been increasingly reported among adolescents worldwide in recent decades following rapid industrialisation and modernisation. ${ }^{(1,2)}$ Abdominal obesity (AO) among adolescents based on waist circumference (WC) measurement has been reported to show a similar trend in many countries. In the United States, the prevalence of $\mathrm{AO}$ in children and adolescents has increased from $10.5 \%$ to $18.0 \%$ between 1988-1994 and 1999-2004. ${ }^{(3)}$ In China, AO prevalence has increased significantly from $4.9 \%$ in 1993 to $11.7 \%$ in $2009 .{ }^{(4)}$ WC was found to have increased at a greater rate than BMI among British children and adolescents when compared with children in China. ${ }^{(4,5)}$

Although BMI has been used clinically to define excessive weight and obesity, it cannot be used to assess the body fat distribution of an individual. ${ }^{(6)}$ WC measurement has been identified as being a better tool to assess body fat distribution, especially for abdominal visceral adiposity, which was shown to be associated with various non-communicable diseases. ${ }^{(7,8)}$ Furthermore, measuring WC is an easier and less expensive method to determine visceral fat in a clinical or epidemiological setting than other gold standard methods, such as computed tomography and magnetic resonance imaging. ${ }^{(9,10)}$ Different anatomical sites are recommended for waist circumference measurement. The site that is most widely used is the midpoint between the lower margin of the last palpable rib and the top of the iliac crest, which was recommended by the World Health Organization $(\mathrm{WHO})$. $^{(1)}$

$\mathrm{AO}$, as diagnosed by the presence of high WC in adults, has been shown to be independently associated with metabolic syndrome, hypertension, cardiovascular disease, diabetes mellitus and other non-communicable diseases, ${ }^{(12-14)}$ as well as increased mortality. ${ }^{(15)}$ Some authors have reported a stronger relationship between WC and these abnormalities than with BMI in adults. ${ }^{(13,16)}$ Similar associations between $\mathrm{AO}$ and these abnormalities have been reported in children and adolescents from Western countries. ${ }^{(17-19)} \mathrm{AO}$ has been reported to be one of the core components of metabolic syndrome, which is associated with insulin resistance and increases the future risk of cardiovascular diseases and diabetes mellitus. ${ }^{(20)}$ Colman et al showed that insulin action improved following weight loss and reduced abdominal fat. ${ }^{(21)}$ Therefore, identifying prevalence and risk factors associated with $\mathrm{AO}$ is an important prerequisite for planning strategies aimed at preventing these non-communicable diseases in the community. Studies in adults showed that diets low in fruits, vegetables and whole grains, and high in processed meat, fast food and soda drinks were associated with increased WC. ${ }^{(22)}$ There were few studies on risk factors associated with AO in adolescents. Other studies with small sample size have shown that physical inactivity $(\mathrm{n}=388)^{(23)}$ and infrequent breakfast consumption $(n=236)^{(24)}$ were significant factors associated with $\mathrm{AO}$ in adolescents. 
In Malaysia, age- and gender-specific WC percentile charts for children and adolescents have recently been developed. These were based on pooled data from all regions of Malaysia, with a sample size of 16,203 adolescents (8,093 boys and 8,110 girls), and participants were from all ethnic groups in proportions that represented the general Malaysian population. The cut-off point to define AO was taken to be the 90th percentile on the WC chart. ${ }^{(25)}$ To the best of our knowledge, no large-scale studies have reported the prevalence and risk factors associated with AO in Malaysian adolescents. Therefore, this study aimed to determine the prevalence of $\mathrm{AO}$ and its associated risk factors among suburban adolescents from the Hulu Langat district of Selangor state in Malaysia.

\section{METHODS}

This cross-sectional study was carried out in secondary schools over a two-month period from 1 July 2013 to 30 August 2013. Five secondary schools in the Hulu Langat district of Selangor were randomly selected from a list of 38 government secondary schools that was provided by the Ministry of Education, Malaysia. Adolescents who were on steroid medication or had endocrine disorders were excluded from the study. In total, 834 students in Form 4 (age range 15-17 years) from the selected schools were eligible and invited to participate in the study. Among these, two declined to participate. The remaining 832 (99.8\%) adolescents consented to participate in the study. Prior to the commencement of the study, approval was obtained from the scientific and ethical review committees of Universiti Tunku Abdul Rahman, the Ministry of Education Malaysia, the State Education Department of Selangor, and the principals of the shortlisted schools. Written parental consent and the consent of the participants were also obtained beforehand.

Anthropometric measurements of participants were carried out by trained second-year medical students at Universiti Tunku Abdul Rahman. Measurements in each category, including height, weight and WC, were carried out by two designated medical students throughout the entire project. Height was measured to the nearest $0.1 \mathrm{~cm}$, while participants were barefoot, using a height rod that was attached to a weighing machine (SECA 220; SECA, Hamburg, Germany). All participants were instructed to stand with their heels, buttocks and shoulders resting lightly against the backing board, so that the Frankfort plane (i.e. the line connecting the superior border of the external auditory meatus with the infraorbital rim) was horizontal and parallel to the floor. Weight was measured using a calibrated weighing machine (SECA 220; SECA, Hamburg, Germany) to the nearest $0.1 \mathrm{~kg}$, with the participants wearing light clothing and barefoot. Participants were asked to stand on the centre of the scale without support and to distribute their weight evenly on both feet. BMI was calculated as weight/(height) ${ }^{2}\left(\mathrm{~kg} / \mathrm{m}^{2}\right){ }^{(26)}$ The BMI classification was based on the age- and gender-specific WHO BMI-for-age chart, ${ }^{(27)}$ with adolescents being diagnosed as overweight when the BMI-for-age z-score was $\geq 1$ and $<2$, and as obese when it was $\geq 2$.

The WC of participants was measured to the nearest $0.1 \mathrm{~cm}$ using a non-extendable measuring tape (SECA, Hamburg,
Germany). The measurement was made at the midpoint between the lower border of the ribs and the iliac crest in a horizontal plane. The measurement was taken at the end of the participant's normal expiration with arms relaxed and at the sides. ${ }^{(11)} \mathrm{AO}$ was diagnosed when the WC of an adolescent was over the 90th percentile for age, based on the age- and gender-specific WC charts for Malaysian children and adolescents developed by Poh et al in 2011. ${ }^{(25)}$ Inter- and intra-rater reliability tests for all anthropometry measurements (i.e. weight, height and WC) were performed prior to the study. The validity of these measurements was verified by a qualified nutritionist. Both the intraclass correlation coefficient and Cronbach's alpha for the anthropometry measurements were $>0.90$. The correlation coefficient for measurements done by the medical students and nutritionist was $>0.90(p<0.05)$.

Information regarding sociodemographic characteristics (e.g. age, gender, ethnicity, parental education, household income and number of siblings), dietary habits, level of physical activity and duration of sleep was obtained from each participant via interview-administered questionnaires. The interviewers were trained second-year medical students. The questionnaire was administered in two languages, Malay and English. It was prepared in English, translated into Malay, then subsequently translated back into English to ensure consistency and accuracy of meaning. The questionnaire was then pretested on ten adolescents with characteristics similar to those of the actual study population.

Questions on dietary habits included regularity of main meals and snacks; frequency of intake of high-fibre food, sweet drinks and fast food; and whether participants were vegetarian. The 73item Food Frequency Questionnaire (FFQ), adapted from Umairah et $\mathrm{al}^{(28)}$ and Abudayya et al, ${ }^{(29)}$ was used to determine the frequency of intake of different types of foods. The list of foods was modified based on foods that were commonly sold in the school canteens and consumed by Malaysian adolescents. The frequency of intake of different types of food was recorded as: ' 0 ' = never; ' 1 ' = rarely; ' 2 ' = 1-3 times/week; ' 3 ' = 4-6 times/week; and ' 4 ' = $\geq 7$ times/ week. All food items in the FFQ were categorised into eight groups: grains/tuber; high-fat foods; poultry/meats/seafood; milk/dairy products; legumes/legume products; processed/fast foods; sweet drinks/desserts; and fruits/vegetables. The total food frequency score for each food group was calculated by summing up the responses for each food group (score range $0-4$ ).

The level of physical activity of the participants was determined using the validated short International Physical Activity Questionnaire (IPAQ). ${ }^{(30)}$ Information on the length of time (i.e. the number of sessions and average time per session) spent on walking, performing moderate- or vigorous-intensity physical activities and sitting, on both weekdays and weekends, was obtained. Questions regarding participation in moderate- or vigorous-intensity physical activities were supplemented with concrete examples of activities commonly performed. A continuous measure was computed from the data as IPAQ score and was reported as median metabolic equivalent (MET) minutes per week. Data from each question was summed up within each item, i.e. vigorous-intensity activity, moderate-intensity activity or walking, to estimate the total amount 
of time spent on physical activity per week. The IPAQ score was estimated by summing up the vigorous MET minutes per week with moderate MET minutes per week and walking MET minutes per week. Vigorous-intensity physical activity was assumed to correspond to $8 \mathrm{METs}$, moderate-intensity physical activity to 4 METs, and walking to 3.3 METs. Participants were then categorised to have low, moderate or high physical activity levels according to the criteria given in the 2003 IPAQ guidelines. ${ }^{(30)}$

Statistical analysis was performed using PASW Statistics for Windows version 18.0 (SPSS Inc, Chicago, IL, USA). Continuous data was presented as mean \pm standard deviation for variables with normal distribution and as median (interquartile range [IQR] 25th-75th percentile) for variables with skewed distribution. All continuous data was tested for normal distribution using the Kolmogorov-Smirnov test. Continuous data that was not normally distributed was log-transformed before inferential analysis. Correlation between WC and other continuous variables was analysed using the Spearman correlation test. The sociodemographic characteristics, dietary habits, level of physical activity and duration of sleep between participants with and without AO were compared. Student's $t$-test was used to compare continuous variables between groups, and chi-square test and Fisher's exact test were used for the analysis of categorical variables. All tests were two-sided. After the potential risk factors $(p<0.10)$ associated with AO were identified based on univariate analysis, multivariate logistic regression analysis was performed to determine the independent risk factors associated with $\mathrm{AO}$. The potential risk factors identified were ethnicity, gender, BMI, irregular meals, not taking dinners daily, vegetarian diet, and FFQ scores for legumes/legume products and sweet drinks/desserts. A p-value $<0.05$ was considered to be statistically significant.

\section{RESULTS}

A total of 832 participants, with a median age of 16 (IQR 15-16) years, were recruited. The demographic data, WC and BMI of all participants are shown in Table I. A majority of parents (father $91.8 \%$; mother $89.8 \%$ ) had completed secondary or higher education levels and a majority $(40.5 \%)$ of families had moderate monthly household income ranging from MYR 2,000 to MYR 5,000. When compared with adolescents with normal WC, adolescents with AO did not have significantly different demographic data except with regard to ethnicity $(p<0.001)$, WC measurements $(p<0.001)$ and BMI $(p<0.001)$. Adolescents with AO had significantly higher WC and BMI. A significantly higher proportion of adolescents with $\mathrm{AO}$ were girls. Among adolescents with AO, a majority (52.1\%) were ethnically Malay.

Fig. 1 shows the frequency distribution of WC measurements for all adolescents. The WC measurements of boys and girls were skewed to the right. A scatter plot of BMI against WC showed that the WC of participants correlated significantly and positively with BMI $(r=0.878 ; p<0.05)$ (Fig. 2). Based on the BMI criteria, the prevalence of overweight and obese adolescents was $14.9 \%$ and $8.3 \%$, respectively. More boys than girls were overweight $(16.9 \%$ vs. $13.3 \%$ ) and obese ( $8.8 \%$ vs. $7.9 \%)$. There was no significant difference in the mean BMI of adolescents with respect to ethnicity $(p=0.065)$, gender $(p=0.804)$, parental education levels (father $p=0.905$; mother $p=0.087)$ and household income $(p=0.407)$.

The prevalence of $\mathrm{AO}$ was $11.3 \%(\mathrm{n}=94)$, which was higher than the prevalence of obesity defined by BMI (8.3\%). Indian adolescents had significantly larger mean WCs $(73.7 \pm 14.0 \mathrm{~cm})$ than Malay $(70.1 \pm 11.4 \mathrm{~cm}, \mathrm{p}=0.036)$ and Chinese $(70.0 \pm$ $9.3 \mathrm{~cm}, \mathrm{p}=0.033)$ adolescents. There were significantly more Indian adolescents with $\mathrm{AO}(22.4 \%)$ than Malay $(12.2 \%)$ and Chinese $(7.7 \%)$ adolescents $(p<0.001)$. Boys had significantly larger WCs $(72.7 \pm 11.2 \mathrm{~cm})$ than girls $(68.5 \pm 10.3 \mathrm{~cm})(\mathrm{p}<0.001)$. However, more girls had AO (13.1\%) than boys $(9.0 \%)$, which was in contrast to our finding of higher prevalence of obesity in boys $(8.8 \%)$ than girls $(7.9 \%)$ based on the age- and genderspecific BMI criteria. There was no significant difference in the WC of adolescents with different parental education levels (father $p=0.727$; mother $p=0.297)$ and household income $(p=0.442)$.

The dietary habits and intake of adolescents are shown in Table II. Only slightly more than half (51.4\%) of the adolescents took their meals regularly (i.e. on time and with regular intervals between meals). Among the adolescents evaluated, 51.6\% regularly skipped breakfast, $24.5 \%$ regularly skipped dinners and $28.1 \%$ took snacks daily. Over one-third (35.9\%) of adolescents took high-fibre food daily and $40.1 \%$ had sweet drinks every day. When compared with adolescents with normal WC, a significantly higher percentage of adolescents with $\mathrm{AO}$ did not take meals regularly $(61.7 \%$ vs. $50.1 \% ; p=0.035)$ and skipped dinners $(41.5 \%$ vs. $22.3 \%$; $p<0.001)$. No other significant difference was found in the dietary habits of adolescents with normal WC and those with AO. The mean FFQ score for sweet drinks/desserts for adolescents with $\mathrm{AO}$ was significantly higher than that of adolescents with normal WC $(15.98 \pm 6.76$ vs. 14.65 $\pm 6.44 ; p=0.034$ ) (Table II). However, there was no significant difference in the FFQ scores for the other food groups between adolescents with normal WC and those with AO ( $p>0.05)$.

Adolescents in our study spent a substantial amount of time sitting down each day, with a mean daily duration of sitting of $463 \pm 65$ minutes (or 7.72 hours; Table III). Even so, a majority of adolescents (53.7\%) reported a high level of physical activity, with a mean IPAQ score of 4,147 $\pm 4,125 \mathrm{MET}$. The mean daily duration of sleep was $7.23 \pm 1.46$ hours. There was no significant difference with respect to the duration of inactivity (e.g. duration of sitting and watching television), sleep and levels of physical activities between adolescents with normal WC and those with AO ( $p>0.05)$.

Logistic regression analysis of potential risk factors (Table IV), after controlling for various confounders, showed that girls $(p=0.002)$, Indian ethnicity $(p=0.003)$, irregular meals $(p=0.042)$ and increasing BMI $(p<0.001)$ were the only significant factors associated with AO. Skipping dinners, being a vegetarian, and FFQ scores for legumes/legume products and sweet drinks/desserts were not significant factors. Nagelkerke's $\mathrm{R}$ squared of the model was 0.850 .

\section{DISCUSSION}

This study targeted adolescents, who are young and more amenable to lifestyle intervention programmes aimed at early 
Table I. Characteristics of adolescents with and without abdominal obesity.

\begin{tabular}{|c|c|c|c|c|}
\hline \multirow[t]{2}{*}{ Variable } & \multicolumn{3}{|c|}{ No. (\%) } & \multirow[t]{2}{*}{$p$-value } \\
\hline & All $(n=832)$ & Normal WC $(n=738)$ & AO $(n=94)$ & \\
\hline Age (yr) & & & & 0.266 \\
\hline 15 & $280(33.7)$ & $248(33.6)$ & $32(34.0)$ & \\
\hline 16 & $529(63.6)$ & $472(64.0)$ & $57(60.6)$ & \\
\hline 17 & $23(2.8)$ & $18(2.4)$ & $5(5.3)$ & \\
\hline Gender & & & & 0.065 \\
\hline Female & $466(56.0)$ & $405(54.9)$ & $61(64.9)$ & \\
\hline Male & $366(44.0)$ & $333(45.1)$ & $33(35.1)$ & \\
\hline Ethnicity & & & & $<0.001^{*}$ \\
\hline Malay & $403(48.4)$ & $354(48.0)$ & $49(52.1)$ & \\
\hline Chinese & $337(40.5)$ & $311(42.1)$ & $26(27.7)$ & \\
\hline Indian & $85(10.2)$ & $66(8.9)$ & $19(20.2)$ & \\
\hline Other & $7(0.8)$ & $7(0.9)$ & $0(0)$ & \\
\hline WC $(\mathrm{cm})$ & & & & $<0.001^{*}$ \\
\hline Median (IQR) & $67.9(63.0-74.6)$ & $66.7(62.4-77.9)$ & $92.3(84.5-98.1)$ & \\
\hline Range & $51.1-119.9$ & $51.1-89.6$ & $80.0-119.9$ & \\
\hline BMI $\left(\mathrm{kg} / \mathrm{m}^{2}\right)^{+}$ & $20.0 \pm 4.6$ & $20.0 \pm 3.0$ & $30.7 \pm 3.7$ & $<0.001^{*}$ \\
\hline Father's age ${ }^{*}$ & {$[n=794]$} & {$[n=705]$} & {$[n=89]$} & 0.475 \\
\hline Age $(y r)^{+}$ & $48.4 \pm 5.4$ & $48.3 \pm 5.3$ & $48.8 \pm 5.8$ & \\
\hline Education level ${ }^{\ddagger}$ & {$[n=788]$} & {$[n=699]$} & {$[n=89]$} & 0.641 \\
\hline Primary school & $65(8.2)$ & $56(8.0)$ & $9(10.1)$ & \\
\hline Secondary school & $424(53.8)$ & $381(54.5)$ & $43(48.3)$ & \\
\hline Pre-university/diploma & $173(22.0)$ & $150(21.5)$ & $23(25.8)$ & \\
\hline University & $126(16.0)$ & $112(16.0)$ & $14(15.7)$ & \\
\hline Mother's age* & {$[n=803]$} & {$[n=713]$} & {$[n=90]$} & 0.121 \\
\hline Age $(y r)^{+}$ & $45.0 \pm 5.2$ & $45.1 \pm 5.2$ & $44.2 \pm 5.3$ & \\
\hline Mother's education level ${ }^{*}$ & {$[n=803]$} & {$[n=711]$} & {$[n=92]$} & 0.925 \\
\hline Primary school & $82(10.2)$ & $71(10.0)$ & $11(12.0)$ & \\
\hline Secondary school & $474(59.0)$ & $420(59.1)$ & $54(58.7)$ & \\
\hline Pre-university/diploma & $158(19.7)$ & $140(19.7)$ & $18(19.6)$ & \\
\hline University & $89(11.1)$ & $80(11.3)$ & $9(9.8)$ & \\
\hline Monthly household income (MYR)* & {$[n=783]$} & {$[n=695]$} & {$[n=88]$} & 0.592 \\
\hline$<1,000$ & $55(7.0)$ & $46(6.6)$ & $9(10.2)$ & \\
\hline $1,000-2,000$ & $221(28.2)$ & $200(28.8)$ & $21(23.9)$ & \\
\hline $2,001-5,000$ & $317(40.5)$ & $282(40.6)$ & $35(39.8)$ & \\
\hline $5,001-10,000$ & $137(17.5)$ & $119(17.1)$ & $18(20.5)$ & \\
\hline$>10,000$ & $53(6.8)$ & $48(6.9)$ & $5(5.7)$ & \\
\hline No. of siblings ${ }^{*}$ & {$[n=822]$} & {$[n=729]$} & {$[n=93]$} & 0.241 \\
\hline Median (IQR) & $3(2-4)$ & $3(2-4)$ & $3(2-4)$ & \\
\hline Range & $0-10$ & $0-10$ & $1-8$ & \\
\hline
\end{tabular}

${ }^{*} \mathrm{p}<0.05$ was statistically significant. + Data presented as mean \pm standard deviation. $¥$ Value of $\mathrm{n}$ is listed in cases where some data was unavailable, and percentages were calculated based on available data. AO: abdominal obesity; BMI: body mass index; IQR: interquartile range; WC: waist circumference

prevention of obesity-related diseases in adulthood. It showed that the prevalence of overweight or obese Malaysian adolescents based on BMI criteria (overall 23.2\%; overweight $14.9 \%$; obese $8.3 \%$ ) was similar to that reported in developed countries. ${ }^{(31)}$ However, this prevalence was much higher than rates reported for Malaysian adolescents by Moy et al in $2004(7.3 \%)^{(32)}$ and Zalilah et al in $2006(19.4 \%){ }^{(33)}$ Our findings suggest that the prevalence of overweight and obese Malaysian adolescents has increased from 2003/2006 to 2013. It should be noted, however, that Moy et al's study was set in an urban area (Kuala Lumpur), ${ }^{(32)}$ while
Zalilah et $\mathrm{al}^{\prime} \mathrm{s}^{(33)}$ was in northern Malaysia, and that both of these studies used 1995 WHO BMI criteria ${ }^{(34)}$ to determine the BMI status of their participants. In contrast, we chose 2007 WHO BMI criteria for our study. ${ }^{(27)}$ For these reasons, data from the earlier studies may not be comparable with ours. The prevalence of overweight and obese adolescents in our study was also similar to that of Indian adolescents (24\%) in Asia in 2008. ${ }^{(35)}$ Nevertheless, the prevalence reported among Malaysian adolescents was lower than that of American adolescents (39.2\%) but higher than that of Korean adolescents (18\%). ${ }^{(36)}$ 

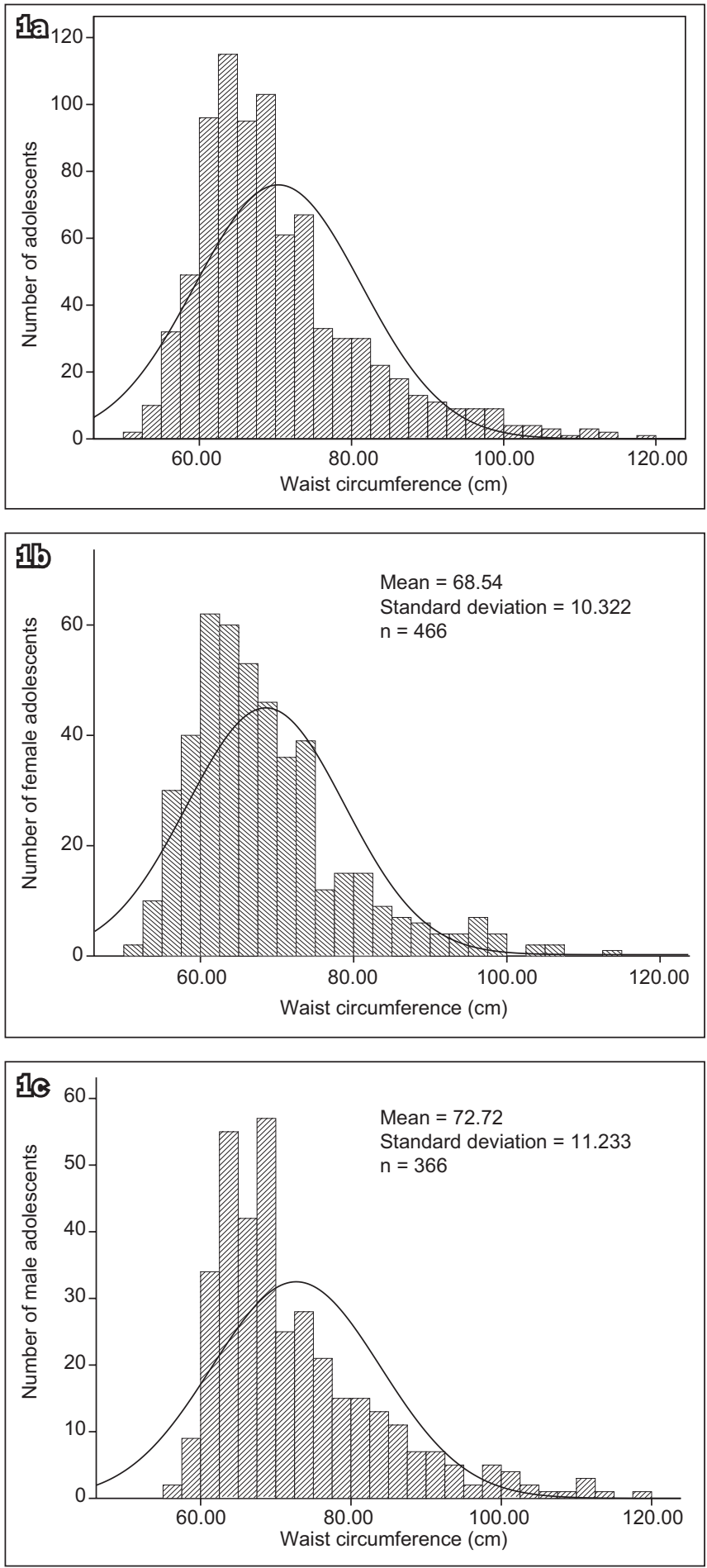

Fig. 1 Charts show frequency distribution of the waist circumference measurements of Malaysian adolescents among (a) all adolescents $(n=832)$, (b) adolescent girls $(n=466)$ and (c) adolescent boys $(n=366)$.

To the best of our knowledge, this was the first study to examine the prevalence of $\mathrm{AO}$ in Malaysian adolescents. Our rate of $11.3 \%$ was lower than the reported prevalence among American adolescents (34.7\%) but higher than the reported rates for Korean $(8.3 \%)^{(36)}$ and Spanish $(9.4 \%)^{(37)}$ adolescents. This finding contradicts those of a systematic review by de Moraes et al in 2011, which reported higher prevalence of AO among adolescents in developing countries than those from developed nations. ${ }^{(38)}$ One possible explanation could be differences in

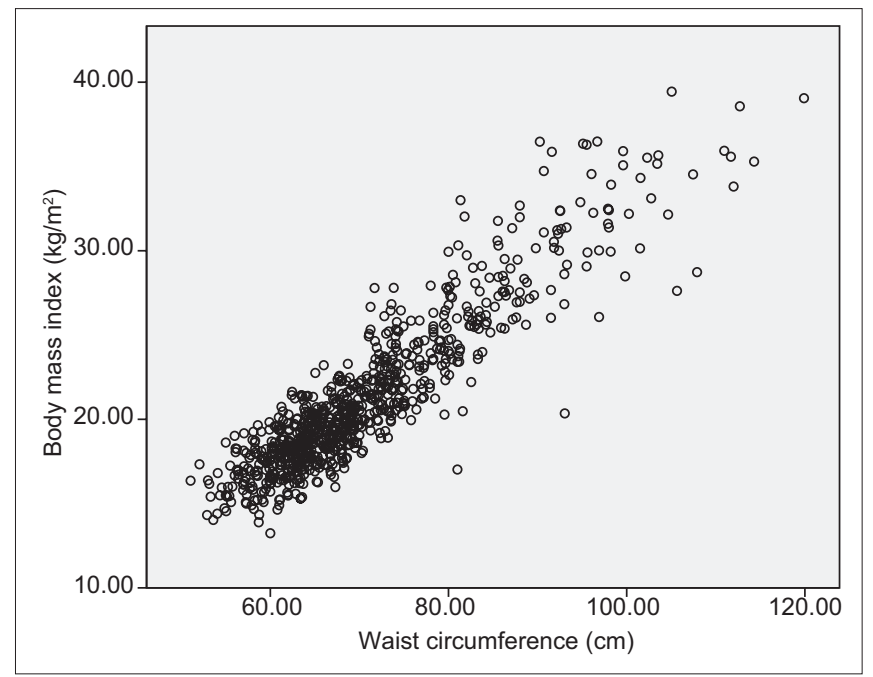

Fig. 2 Scatter plot shows the relationship between body mass index and waist circumference (Spearman correlation coefficient $r=0.878 ; p<0.05$ ).

the WC cut-off values used for defining AO in adolescents from different populations in these various studies, with resultant wide variations in the prevalence found.

The WC of adolescents in our study correlated strongly and significantly with BMI. However, the prevalence of obesity according to WC was $3.0 \%$ higher than that determined based on BMI, indicating that approximately $3.0 \%$ of adolescents who were not obese had $\mathrm{AO}$. The use of $\mathrm{BMI}$ as an indicator of obesity may thus underestimate the prevalence of obesity. The findings of our study were in agreement with earlier reports that WC was a better indicator for obesity than BMI. ${ }^{(39,40)}$

After controlling for various potential risk factors, multivariate logistic regression analysis confirmed that only four risk factors were significantly associated with $\mathrm{AO}$ : increasing $\mathrm{BMI}$; female gender; Indian ethnicity; and irregular meals. Our finding that AO was significantly more common among Malaysian adolescents of Indian ethnicity $(p<0.05)$ is consistent with previous studies, such as the National Health and Morbidity Survey III, which reported the prevalence of $\mathrm{AO}$ to be highest among Indian adults in the Malaysian population. ${ }^{(41)}$ Taken together, these findings hint at genetic (ethnic in origin) and environmental (e.g. dietary habits) factors, and interactions that may play roles in predisposing individuals to $\mathrm{AO}$ in Malaysia.

In this study, more participants skipped breakfast than lunch and dinner. This is consistent with other studies that have reported breakfast as the most commonly skipped meal among adolescents. ${ }^{(42)}$ However, unlike the findings of other investigators, no significant association was found in our study between skipping breakfast and AO among Malaysian adolescents. ${ }^{(24,43)}$ Instead, we found that taking meals irregularly was a significant risk factor associated with AO after controlling for various confounders. This could be due to the decreased thermic effect of food after an irregular meal pattern when compared with individuals with a regular meal pattern, as reported in a study on healthy lean women, ${ }^{(44)}$ resulting in the development of AO in the former group.

Previous cross-sectional studies, longitudinal studies and randomised clinical trials have reported significant associations 
Table II. Dietary habits and FFQ scores of adolescents with and without abdominal obesity.

\begin{tabular}{|c|c|c|c|c|}
\hline \multirow[t]{2}{*}{ Variable } & \multicolumn{3}{|c|}{ No. (\%)/mean \pm standard deviation } & \multirow[t]{2}{*}{$p$-value } \\
\hline & All $(n=832)$ & Normal WC $(n=738)$ & AO $(n=94)$ & \\
\hline Regular meal intake & & & & $0.035^{*}$ \\
\hline Yes & $404(48.6)$ & 368 (49.9) & $36(38.3)$ & \\
\hline No & $428(51.4)$ & $370(50.1)$ & $58(61.7)$ & \\
\hline Breakfast intake $^{+}$ & {$[n=829]$} & {$[n=736]$} & {$[\mathrm{n}=93]$} & 0.380 \\
\hline Daily & $401(48.4)$ & $360(48.9)$ & $41(44.1)$ & \\
\hline Not daily & $428(51.6)$ & $376(51.1)$ & $52(55.9)$ & \\
\hline Lunch intake & & & & 0.771 \\
\hline Daily & $699(84.0)$ & $621(84.1)$ & $78(83.0)$ & \\
\hline Not daily & $133(16.0)$ & $117(15.9)$ & $16(17.0)$ & \\
\hline Dinner intake $^{+}$ & {$[n=830]$} & {$[n=736]$} & & $<0.001^{*}$ \\
\hline Daily & $627(75.5)$ & $572(77.7)$ & $55(58.5)$ & \\
\hline Not daily & $203(24.5)$ & $164(22.3)$ & $39(41.5)$ & \\
\hline Snack intake ${ }^{+}$ & {$[n=829]$} & {$[n=735]$} & & 0.371 \\
\hline Daily & $233(28.1)$ & $212(28.8)$ & $21(22.3)$ & \\
\hline Weekly & $344(41.5)$ & $300(40.8)$ & $44(46.8)$ & \\
\hline Rarely & $252(30.4)$ & $223(30.3)$ & $29(30.9)$ & \\
\hline High fibre intake ${ }^{+}$ & {$[n=830]$} & {$[n=736]$} & & 0.479 \\
\hline Daily & $298(35.9)$ & $262(35.6)$ & $36(38.3)$ & \\
\hline Weekly & $312(37.6)$ & $280(38.0)$ & $32(34.0)$ & \\
\hline Rarely & $220(26.5)$ & $194(26.4)$ & $26(27.7)$ & \\
\hline Sweet drink intake ${ }^{+}$ & {$[n=830]$} & {$[n=736]$} & & 0.225 \\
\hline Daily & $333(40.1)$ & $295(40.1)$ & $38(40.4)$ & \\
\hline Weekly & $321(38.7)$ & $279(37.9)$ & $42(44.7)$ & \\
\hline Rarely & $176(21.2)$ & $162(22.0)$ & $14(14.9)$ & \\
\hline Fast food intake & & & & 0.193 \\
\hline Daily & $35(4.2)$ & $34(4.6)$ & $1(1.1)$ & \\
\hline Weekly & $366(44.0)$ & $327(44.3)$ & $39(41.5)$ & \\
\hline Rarely & $431(51.8)$ & $377(51.1)$ & $54(57.4)$ & \\
\hline Vegetarian ${ }^{+}$ & {$[n=829]$} & {$[n=735]$} & & 0.087 \\
\hline Yes & $28(3.4)$ & $22(3.0)$ & $6(6.4)$ & \\
\hline No & $801(96.6)$ & $713(97.0)$ & $88(93.6)$ & \\
\hline \multicolumn{5}{|l|}{ FFQ score } \\
\hline Grains/tuber & $17.38 \pm 5.53$ & $17.35 \pm 5.60$ & $16.70 \pm 4.99$ & 0.436 \\
\hline High-fat foods & $20.47 \pm 8.14$ & $20.33 \pm 8.06$ & $21.57 \pm 8.70$ & 0.153 \\
\hline Poultry/meat/seafood & $8.16 \pm 4.28$ & $8.17 \pm 4.29$ & $8.04 \pm 4.21$ & 0.653 \\
\hline Milk/dairy products & $4.70 \pm 3.13$ & $4.67 \pm 3.09$ & $4.96 \pm 3.41$ & 0.193 \\
\hline Legumes/legume products & $4.89 \pm 2.86$ & $4.81 \pm 2.87$ & $5.51 \pm 2.77$ & 0.050 \\
\hline Processed/fast foods & $8.54 \pm 3.42$ & $8.50 \pm 3.44$ & $8.81 \pm 3.21$ & 0.303 \\
\hline Sweet drinks/desserts & $14.80 \pm 6.49$ & $14.65 \pm 6.44$ & $15.98 \pm 6.76$ & $0.034^{*}$ \\
\hline Fruits/vegetables & $11.19 \pm 4.12$ & $11.22 \pm 4.14$ & $10.93 \pm 3.99$ & 0.679 \\
\hline
\end{tabular}

All FFQ score values were transformed to logarithms for analysis. Independent $t$-test was used to analyse continuous data while chi-square test was used to analyse category data. ${ }^{*} p<0.05$ was statistically significant. +Value of $n$ is listed in cases where some data was unavailable, and percentages were calculated based on available data. AO: abdominal obesity; FFQ: Food Frequency Questionnaire; WC: waist circumference

between high consumption of sweetened beverages and adiposity in children and adolescents. ${ }^{(45-48)}$ In our study, although univariate analysis showed a similar association (as indicated by the significantly higher FFQ score for sweet foods/desserts among adolescents with $\mathrm{AO}$ ), multivariate logistic regression analysis did not show this association to be statistically significant after controlling for various potential confounders. We also did not find intake of legumes, cereals and grains to be significant factors associated with AO. ${ }^{(49-51)}$ Our findings did not support other studies that found the consumption of more legumes to be positively associated with obesity or AO ${ }^{(51)}$ Further studies are needed to determine whether the exact portion size of legume intake by Malaysian adolescents could explain this variance between studies.

This study was not without limitations. Most of the information was collected via interviews, which may entail recall bias. 
Table III. Comparison of levels of physical activity between adolescents with and without abdominal obesity.

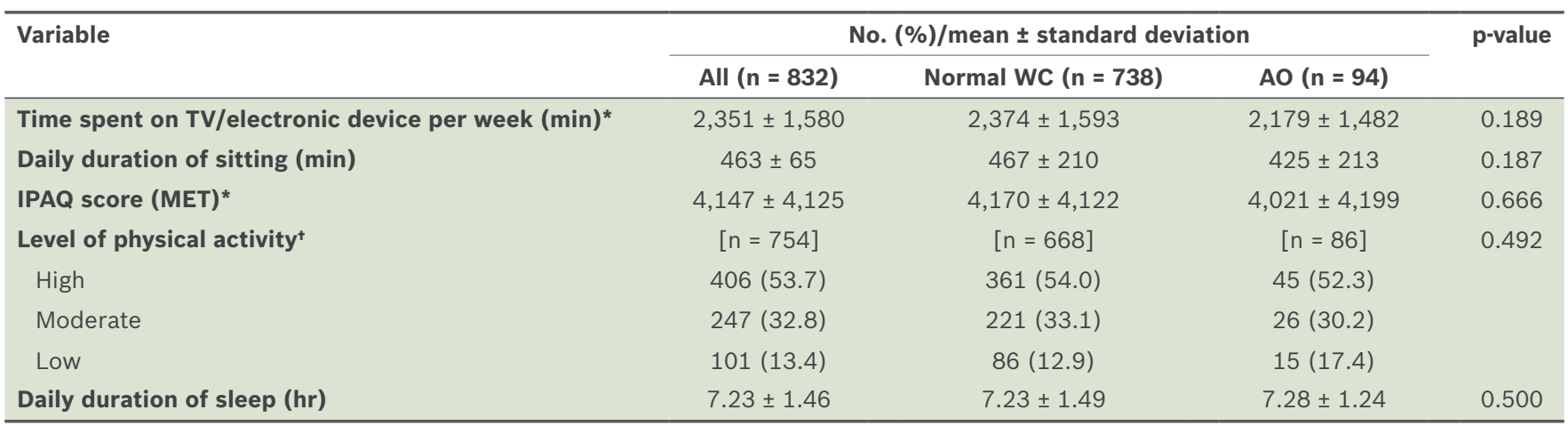

*Values were transformed to logarithmic scale for analysis. Independent $t$-test was used to analyse continuous data, while chi-square test was used to analyse categorical data. +Value of $\mathrm{n}$ is listed in cases where some data was unavailable, and percentages were calculated based on available data. AO: abdominal obesity; IPAQ: International Physical Activity Questionnaire; MET: metabolic equivalent; WC: waist circumference

Table IV. Results of logistic regression analysis of potential risk factors associated with abdominal obesity $(\mathbf{n}=\mathbf{8 3 2}$ ).

\begin{tabular}{|c|c|c|c|}
\hline Variable & $\beta$ & Adjusted OR (95\% CI) & p-value \\
\hline Female gender & 1.955 & $7.064(2.087-23.913)$ & $0.002 *$ \\
\hline Indian ethnicity & 2.319 & $10.164(2.182-47.346)$ & $0.003^{*}$ \\
\hline Irregular meals & 1.161 & $3.193(1.043-9.774)$ & $0.042^{*}$ \\
\hline Body mass index & 1.053 & $2.867(2.216-3.710)$ & $<0.001^{*}$ \\
\hline Not taking dinners daily & -0.662 & $0.516(0.179-1.488)$ & 0.221 \\
\hline \multicolumn{4}{|l|}{ FFQ score } \\
\hline Sweet drinks/desserts & -0.027 & $0.974(0.891-1.064)$ & 0.557 \\
\hline Legumes/legume products & 0.16 & $1.102(0.934-1.105)$ & 0.717 \\
\hline Constant & -31.963 & & $<0.001^{*}$ \\
\hline
\end{tabular}

${ }^{*} p<0.05$ was statistically significant. $\beta$ : beta coefficient; $\mathrm{Cl}$ : confidence interval; FFQ: Food Frequency Questionnaire; OR: odds ratio

Also, information on the portion size of food intake was not obtained. However, a previous study found that including data on portion size in the FFQ did not give significant extra information when estimating usual food intake. ${ }^{(52)}$ Although our study showed that $\mathrm{AO}$ was associated with irregular meal intake, this association may be due to the phenomenon of reverse causation, as participants with abdominal obesity may have a higher tendency toward irregular meal intake in an attempt to lose weight and, consequently, more frequently report the practice. As the five schools included in the present study were selected before participants from each school were invited to participate, the participants were nested within each school. This practice resulted in data clustering, which could possibly have affected the statistical significance of our results. Furthermore, the study was conducted only on Form 4 (year 11) students aged 15-17 years. It is uncertain whether the prevalence and risk factors of $\mathrm{AO}$ among Malaysian adolescents below or above this age range would be similar. However, in view of the large sample size and multiethnicity of the participants recruited, our findings were, to some extent, representative of all adolescents from suburban areas in Malaysia.

In conclusion, AO prevalence was high among adolescents in a suburban district of Selangor state, Malaysia. Factors such as female gender, Indian ethnicity, irregular meal intake and increasing BMI significantly increased the risk of $\mathrm{AO}$ among these adolescents. Lifestyle interventions, including changes in dietary habits, may be needed to reduce AO in this group of Malaysian adolescents, particularly among girls and those of Indian ethnicity.

\section{ACKNOWLEDGEMENTS}

We would like to extend our appreciation to all participants and their parents. We are grateful to the Ministry of Education Malaysia, the State Education Department (Jabatan Pendidikan Negeri) and the principals of the participating schools for granting us permission to carry out the study. We would also like to thank the 2013 second-year medical students at Universiti Tunku Abdul Rahman for their contribution. Research funds were granted by the Faculty of Medicine and Health Sciences, Universiti Tunku Abdul Rahman, Malaysia.

\section{REFERENCES}

1. Lobstein T, Baur L, Uauy R; IASO International Obesity Task Force. Obesity in children and young people: a crisis in public health. Obes Rev 2004; 5 Suppl 1:4-104.

2. Khambalia AZ, Seen LS. Trends in overweight and obese adults in Malaysia (1996-2009): a systemic review. Obes Rev 2010; 11:403-12.

3. Li C, Ford ES, Mokdad AH, Cook S. Recent trends in waist circumference and waist-height ratio among US children and adolescents. Pediatrics 2006; 118:e1390-8.

4. Liang YJ, Xi B, Song AQ, Liu JX, Mi J. Trends in general and abdominal obesity among Chinese children and adolescents 1993-2009. Pediatr Obes 2012; 7:355-64.

5. McCarthy HD, Ellis SM, Cole TJ. Central overweight and obesity in British youth aged 11-16 years: cross sectional surveys of waist circumference. BMJ 2003; 326:624

6. Janssen I, Katzmarzyk PT, Ross R. Waist circumference and not body mass index 
explains obesity-related health risk. Am J Clin Nutr 2004; 79:379-84.

7. Okosun IS, Forrester TE, Rotimi CN, et al. Abdominal adiposity in six population of West African descent: prevalence and population attributable fraction of hypertension. Obes Res 1999; 7:453-62.

8. Brambilla P, Bedogni G, Moreno LA, et al. Crossvalidation of anthropometry against magnetic resonance imaging for the assessment of visceral and subcutaneous adipose tissue in children. Int J Obes (Lond) 2006; 30:23-30.

9. Ribeiro-Filho FF, Faria AN, Azjen S, Zanella MT, Ferreira SR. Methods of estimation of visceral fat: advantages of ultrasonography. Obes Res 2003; 11:1488-94.

10. Shen W, Wang Z, Punyanita M, et al. Adipose tissue quantification by imaging methods: a proposed classification. Obes Res 2003; 11:5-16.

11. Wang J, Thornton JC, Bari S, et al. Comparison of waist circumferences measured at 4 sites. Am J Clin Nutr 2003; 77:379-84.

12. Wang Y, Rimm EB, Stampfer MJ, Willett WC, Hu FB. Comparison of abdominal adiposity and overall obesity in predicting risk of type 2 diabetes among men. Am J Clin Nutr 2005; 81:555-63.

13. Yusuf S, Hawken S, Ounpuu S, et al; INTERHEART Study Investigators. Obesity and risk of myocardial infarction in 27,000 participants from 52 countries: a case-control study. Lancet 2005; 366:1640-9.

14. Sreeramareddy $\mathrm{CT}$, Chew WF, Poulsaeman V, et al. Blood pressure and its associated factors among primary school children in suburban Selangor, Malaysia: A cross-sectional survey. J Family Community Med 2013; 20:90-7.

15. Katzmarzyk PT, Craig CL. Independent effects of waist circumference and physical activity on all-cause mortality in Canadian women. Appl Physiol Nut Metab 2006; 31:271-6.

16. Huang LH, Liao YL, Hsu CH. Waist circumference is a better predictor than body mass index of insulin resistance in type 2 diabetes. Obes Res Clin Pract 2012; 6:e263-346

17. Hirschler V, Aranda C, Calcagno Mde L, Maccalini G, Jadzinksy M. Can wais circumference identify children with the metabolic syndrome? Arch Pediatr Adolesc Med 2005; 159:740-4

18. Maffeis C, Corciulo N, Livieri C, et al. Waist circumference as a predictor of cardiovascular and metabolic risk factors in obese girls. Eur J Clin Nutr 2003; 57:566-72.

19. Gopinath B, Baur LA, Garnett S, et al. Body mass index and waist circumference are associated with blood pressure in preschool-aged children. Ann Epidemiol 2011; 21:351-7.

20. Alberti KG, Zimmet $P$, Shaw J. Metabolic syndrome--a new world-wide definition. A Consensus Statement from the International Diabetes Federation. Diabet Med 2005; 23:469-80.

21. Colman E, Katzel LI, Rogus E, et al. Weight loss reduces abdominal fat and improves insulin action in middle-aged and older men with impaired glucose tolerance. Metabolism 1995; 44:1502-8.

22. Newby PK, Muller D, Hallfrisch J, et al. Dietary patterns and changes in body mass index and waist circumference in adults. Am J Clin Nutr 2003; 77:1417-25.

23. Pietiläinen $\mathrm{KH}$, Kaprio J, Borg $\mathrm{P}$, et al. Physical inactivity and obesity: a vicious circle. Obesity (Silver Spring) 2008; 16:409-14

24. Nurul-Fadhilah A, Teo PS, Huybrechts I, Foo LH. Infrequent breakfas consumption is associated with higher body adiposity and abdominal obesity in Malaysian school-aged adolescents. PLoS One 2013; 8:e59297.

25. Poh BK, Jannah AN, Chong LK, et al. Waist circumference percentile curves for Malaysian children and adolescents aged 6.0-16.9 years. Int J Pediatr Obes $2011 ; 6: 229-35$

26. Norton K, Olds T. Anthropometrica: A Textbook of Body Measurement for Sports and Health Courses. Sydney: University of New South Wales Press, 1996.

27. World Health Organization. Growth reference 5-19 years. Available at: http:// www.who.int/growthref/who2007 bmi for age/en/. [5 January 2013].

28. Umairah SN, Yahya BT, Datin M, Yusof SM. Relationship between dietary pattern and body mass index among primary school children. Asian J Clin Nutr 2012 4:142-50.

29. Abudayya AH, Stigum H, Shi Z, Abed Y, Holmboe-Ottesen G. Sociodemographic correlates of food habits among school adolescents (12-15 year) in North Gaza Strip. BMC Public Health 2009; 9:185
30. Craig $\mathrm{CL}$, Marshall $\mathrm{AL}$, Sjöström $\mathrm{M}$, et al. International physical activity questionnaire: 12-country reliability and validity. Med Sci Sports Exerc 2003; 35:1381-95.

31. Ng M, Fleming $\mathrm{T}$, Robinson $\mathrm{M}$, et al. Global, regional, and national prevalence of overweight and obesity in children and adults during 1980-2013: a systematic analysis for the Global Burden of Disease Study 2013. Lancet 2014; 384:766-81.

32. Moy FM, Gan CY, Zaleha MK. Body mass status of school children and adolescents in Kuala Lumpur, Malaysia. Asia Pac J Clin Nutr 2004; 13:324-9.

33. Zalilah MS, Mirnalini K, Khor GL, et al. Estimates and distribution of body mass index in a sample of Malaysian adolescents. Med J Malaysia 2006; 61:48-58.

34. World Health Organization. Adolescents. In: Physical status: the use and interpretation of anthropometry, WHO Technical Series Report No. 854. Geneva: WHO 1995; 263-308.

35. Bhardwaj S, Misra A, Khurana L, et al. Childhood obesity in Asian Indians: a burgeoning cause of insulin resistance, diabetes and sub-clinical inflammation. Asia Pac J Clin Nutr 2008; 17 Suppl 1:172-5.

36. Park J, Hilmers DC, Mendosa JA, et al. Prevalence of metabolic syndrome and obesity in adolescents aged 12 to 19 years: comparison between the United States and Korea. J Korean Med Sci 2010; 25:75-82.

37. Schröder HS, Ribas L, Koebnick C, et al. Prevalence of abdominal obesity in Spanish children and adolescents. Do we need waist circumference measurements in pediatric practice? PLoS One 2014; 9:e87549.

38. de Moraes AC, Fadoni RP, Ricardi LM, et al. Prevalence of abdominal obesity in adolescents: a systematic review. Obes Rev 2011; 12:69-77.

39. Booth ML, Hunter C, Gore CJ, Bauman A, Owen N. The relationship between body mass index and waist circumference: implications for estimates of the population prevalence of overweight. Int J Obes Relat Metab Disord 2000; 24:1058-61.

40. Bibiloni Mdel M, Pons A, Tur JA. Defining body fatness in adolescents: a proposal of the AFAD-A classification. PLoS One 2013; 8:e55849.

41. Kee CC Jr, Jamaiyah H, Noor Safiza MN, et al. Abdominal obesity in Malaysian adults: National Health and Morbidity Survey III (NHMS III, 2006). Mal J Nutr 2008; 14:125-35.

42. Mazur A, Klimek K, Telega G, et al. Risk factors for obesity development in school children from south-eastern Poland. Ann Agric Environ Med 2008; 15:281-5.

43. Alexander KE, Ventura EE, Spruijt-Metz D, et al. Association of breakfast skipping with visceral fat and insulin indices in overweight Latino youth. Obesity (Silver Spring) 2009; 17:1528-33.

44. Farshchi HR, Taylor MA, Macdonald IA. Decreased thermic effect of food after an irregular compared with a regular meal pattern in healthy lean women. Int J Obes Relat Metab Disord 2004; 28:653-60.

45. Collison KS, Zaidi MZ, Subhani SN, et al. Sugar-sweetened carbonated beverage consumption correlates with $\mathrm{BMI}$, waist circumference, and poor dietary choices in school children. BMC Public Health 2010; 10:234.

46. Fiorito LM, Marini M, Francis LA, Smiciklas-Wright H, Birch LL. Beverage intake of girls at age 5 y predicts adiposity and weight status in childhood and adolescence. Am J Clin Nutr 2009; 90:935-42.

47. Ebbeling CB, Feldman HA, Osganian SK, et al. Effects of decreasing sugarsweetened beverage consumption on body weight in adolescents: a randomized, controlled pilot study. Pediatrics 2006; 117:673-80.

48. Malik VS, Schulze MB, Hu FB. Intake of sugar-sweetened beverages and weight gain: a systematic review. Am J Clin Nutr 2006; 84:274-88.

49. Bradlee ML, Singer MR, Qureshi MM, Moore LL. Food group intake and central obesity among children and adolescents in the Third National Health and Nutrition Examination Survey (NHANES III). Public Health Nutr 2010; 13:797-805

50. McKeown NM, Troy LM, Jacques PF, et al. Whole- and refined-grain intakes are differentially associated with abdominal visceral and subcutaneous adiposity in healthy adults: the Framingham Heart Study. Am J Clin Nutr 2010; 92:1165-71.

51. Williams PG, Grafenauer SJ, O'Shea JE. Cereal grains, legumes, and weight management: a comprehensive review of the scientific evidence. Nutr Rev 2008; 66:171-82

52. Tjonneland A, Haraldsdóttir J, Overvad K, et al. Influence of individually estimated portion size data on the validity of a semiquantitative food frequency questionnaire. Int J Epidemiol 1992; 21:770-7. 